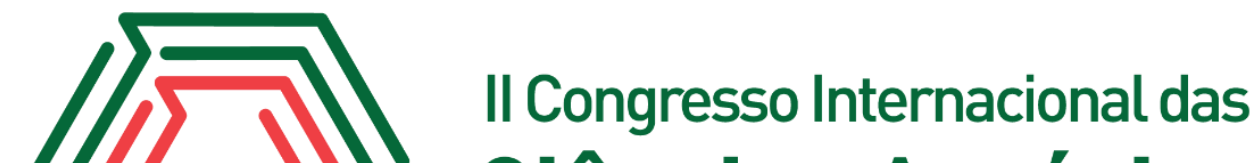 Ciências Agrárias COINTER - PDVAgro 2017
}

\section{RESPOSTA DA RÚCULA EM FUNÇÃO DA ADUBAÇÃO POTÁSSICA}

Anna Yanka De Oliveira Santos ${ }^{1}$; Martiliana Mayani Freire ${ }^{2}$; Éric George Morais ${ }^{3}$; Ellen Rachel Evaristo de Morais ${ }^{4}$; Gualter Guenther Costa da Silva ${ }^{5}$

\section{Introdução}

A rúcula (Eruca sativa Miller) é uma hortaliça de rápido crescimento e de fácil cultivo, bastante conhecida pelo seu gosto amargo. Apresenta uma boa adaptação em diferentes regiões e uma baixa exigência hídrica, o que colabora para que essa hortaliça se torne uma das folhosas mais produzidas no mundo.

O uso da adubação mineral é uma forma de aumentar a qualidade do produto e potencializar os ganhos econômicos de produção. Com isso, atendendo a demanda do mercado que se faz cada vez mais exigente, o presente trabalho teve como objetivo avaliar o efeito de diferentes doses de potássio no desenvolvimento de plantas de rúcula.

\section{Fundamentação Teórica}

Devido o seu rápido crescimento vegetativo, as hortaliças podem apresentar desordens nutricionais empregadas à velocidade de crescimento e ocorrência dos processos metabólicos, além, de altas taxas de extração e exportação de nutrientes necessários para o seu desenvolvimento (FILGUEIRA, 2000).

As recomendações de adubação para a cultura da rúcula ainda são bastante escassas. Por isso, muitas vezes são utilizadas recomendações pertencentes culturas de famílias deferentes, mas que apresentam características fenotípicas semelhantes à rúcula, como por exemplo, a alface. Também, não existe recomendação específica para diferentes estações do ano, ou para plantios submetidos a diferentes condições, como cultivos em campo ou sob local protegido (PURGUERIO, 2005).

\footnotetext{
${ }^{1}$ Graduando em Agronomia, Universidade Federal do Rio Grande do Norte, annayanka12@hotmail.com

${ }^{2}$ Graduada em Agronomia, Universidade Federal do Rio Grande do Norte, martilianafreire11@gmail.com

${ }^{3}$ Graduanda em Agronomia, Universidade Federal do Rio Grande do Norte, ericmoraais@gmail.com

${ }^{4}$ Graduanda em Agronomia, Universidade Federal do Rio Grande do Norte, ellen-rachel@hotmail.com

${ }^{5}$ Prof. Doutor, Universidade Federal do Rio Grande do Norte, gualtermve@gmail.com
} 
O potássio tem uma importante atuação na regulagem de abertura e fechamento dos estômatos, na síntese de proteínas e carboidratos, e no armazenamento de açúcares e amido. Além disso, ele contribui para o crescimento vegetativo da folhosa, melhor utilização da água e favorece a resistência a possíveis patógenos provedores de doenças (Malavolta et al., 2006). Segundo Viana e Kiehl (2010) a presença do potássio nas plantas também contribui para o aproveitamento do nitrogênio. Influenciando na sua absorção, assimilação, e consequentemente no aumento da produção dos plantios.

\section{Metodologia}

O experimento foi desenvolvido nas dependências do Grupo de Estudo em Solos (GESOLO), situado na Escola Agrícola de Jundiaí da Universidade Federal do Rio Grande do Norte - UFRN, Campus Macaíba- RN. O solo da área experimental é classificado como Neossolo flúvico, de textura arenosa. O clima na classificação de Koppen está entre os tipos As’ e BSh', apresentando uma estação chuvosa (verão) e quente, e outra, caracterizada pelo inverno seco. O experimento teve início em fevereiro, e término em abril de 2017.

O delineamento experimental foi realizado em blocos ao acaso, com seis tratamentos e quatro repetições. Foi utilizada a Rúcula cv Cultivada, cujas mudas foram produzidas em bandejas de isopor com células individualizadas utilizando composto orgânico como substrato, permanecendo em ambiente protegido durante 21 dias, contados a partir da semeadura. As parcelas continham as dimensões de $1,0 \times 1,0$ metros, espaçadas $0,25 \times 0,25$ metros. Cada parcela era constituída por 16 plantas, sendo as 4 centrais, a parcela útil para efeito de coleta de dados. Foi realizada a calagem 30 dias antes do transplantio para a elevação do $\mathrm{pH}$.

Utilizou-se como fonte o cloreto de potássio nas concentrações 0, 40, 190, 340, 490 e $640 \mathrm{~kg}$ de potássio por hectare. $\mathrm{Na}$ adubação de base foi aplicado $340 \mathrm{Kg} / \mathrm{ha}$ de $\mathrm{P}_{2} \mathrm{O}_{5}, 160 \mathrm{Kg} / \mathrm{ha}$ de N, 20 $\mathrm{Kg} / \mathrm{ha}$ de $\mathrm{S}$ e $1 \mathrm{Kg} / \mathrm{ha}$ de B, na forma de superfosfato triplo, ureia, sulfato de amônia e FTE BR 12, respectivamente. Foi realizada uma adubação de fundação antes do transplantio das mudas, aplicando $20 \%$ do total de nitrogênio e potássio, e $100 \%$ do fosforo e boro; e duas adubações de cobertura aos 11 e 21 dias após o transplantio das mudas, aplicando $40 \%$ do total de nitrogênio e potássio em cada adubação. As variáveis analisadas foram: altura da parte aérea, número de folhas, massa da matéria fresca e massa da matéria seca. A colheita da rúcula ocorreu 35 dias após o transplantio. 
Os dados foram submetidos à análise de variância e o efeito das doses de potássio verificados por análise de regressão a 5\% de significância.

\section{Resultados e Discussões}

Comparando as médias das variáveis altura da parte aérea (APA), número de folhas e matéria seca (MMS), observou-se que não houveram diferenças significativas no desenvolvimento da cultura da rúcula para estas variáveis (Tabela 1), no entanto houve efeito significativo entre as médias de massa de matéria fresca (MMF), pelo teste de Tukey, ao nível de 5\%. Apesar dos resultados não diferirem estatisticamente, para as variáveis número de folhas e matéria seca, o tratamento 3 (490 kg ha-1) foi o que apresentou maiores valores, inferido que a dose $490 \mathrm{~kg}$ ha-1 de cloreto de potássio pode ser indicada quando se deseja ao aumento de produção de biomassa, visto que foi nessa dose se obteve as maiores médias de acúmulo de matéria fresca.

Tabela 1. Valores médios da altura da parte aérea (APA), número de folhas (NF), massa da matéria fresca (MMF), e massa da matéria seca (MMS), obtidos para a rúcula cv. Cultivada aos 35 dias após o transplantio, em função de doses de potássio. Fonte: Própria

\begin{tabular}{ccccc}
\hline Tratamentos & APA (cm) & NF & MMF (g) & MMS(g) \\
\hline T1 & $26,31 \mathrm{a}$ & $55,37 \mathrm{a}$ & $188,59 \mathrm{~b}$ & $15,01 \mathrm{a}$ \\
T2 & $28,29 \mathrm{a}$ & $62,15 \mathrm{a}$ & $225,81 \mathrm{ab}$ & $16,87 \mathrm{a}$ \\
T3 & $29,29 \mathrm{a}$ & $66,15 \mathrm{a}$ & $263,38 \mathrm{a}$ & $18,10 \mathrm{a}$ \\
T4 & $28,68 \mathrm{a}$ & $58,20 \mathrm{a}$ & $223,99 \mathrm{ab}$ & $16,68 \mathrm{a}$ \\
T5 & $26,74 \mathrm{a}$ & $57,30 \mathrm{a}$ & $222,20 \mathrm{ab}$ & $16,18 \mathrm{a}$ \\
T6 & $29,20 \mathrm{a}$ & $54,96 \mathrm{a}$ & $252,97 \mathrm{a}$ & $17,05 \mathrm{a}$ \\
\hline CV $(\%)$ & 4,67 & 15,52 & 12,18 & 9,88 \\
DMS & 3,01 & 21,05 & 64,24 & 3,78 \\
\hline
\end{tabular}

*Médias seguidas de mesma letra não diferem entre si estatisticamente, pelo teste de Tukey a $5 \%$ de probabilidade.

Corroborando com os resultados obtidos para a variável matéria fresca, Mota et al., (2002), relatou em seu estudo que o aumento da dose $\mathrm{K} 2 \mathrm{O}$ propicia o incremento de biomassa na produção total da alface cv. Americana.

Possivelmente, o efeito não significativo para NF, MMS e APA, no presente trabalho, está atrelado a processos fisiológicos de incorporação de nutrientes, visto que quando o potássio é fornecido em abundância ocorre um "consumo de luxo", desencadeando um desequilíbrio nutricional, que pode interferir na absorção de outros nutrientes (MARODIN et al., 2010). 
Figura 1: Massa da matéria fresca de plantas de rúcula, em função de doses de potássio. Fonte: Própria

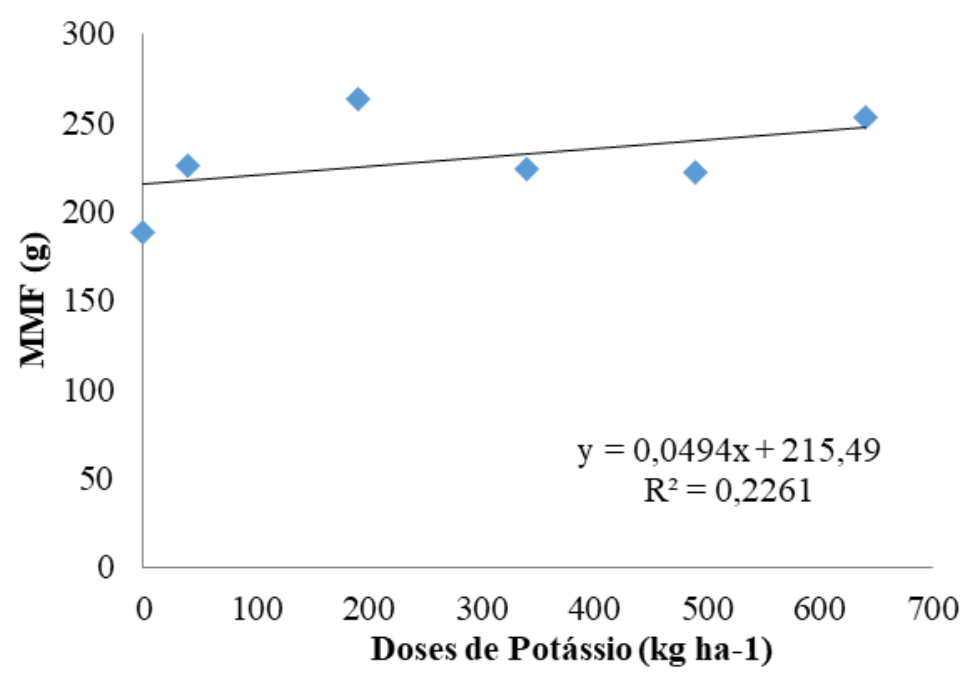

Para massa de matéria fresca (MMF) teve-se um ajuste ao modelo linear de regressão, onde a maior produção foi atingida com $190 \mathrm{~kg} \mathrm{ha}^{-1}$ de P. Isso mostra uma melhor resposta da cultura a doses menores de adubação potássica, reduzindo os cultos com altas dosagens de adubo(Figura 1).

\section{Conclusões}

A variável massa de matéria fresca é influenciada pela adubação potássica com ajuste a modelo linear de regressão.

As variáveis altura da parte aérea, número de folhas, e massa da matéria seca não são influenciadas pela adubação potássica.

\section{Referências}

FILGUEIRA, F.A.R. Novo manual de olericultura: agrotecnologia moderna na produção e comercialização de hortaliças. Viçosa: UFV, 2000. 402 p.

MALAVOLTA, E. Manual de nutrição mineral de plantas. São Paulo. Ceres. 2006. 638 p.

MARODIN, J. C. et al. Qualidade físico-química de frutos de morangueiro em função da adubação potássica. Scientia Agraria Paranaensis, V. 9, no 3, p 50-57, 2010.

MOTA, J.H.; SOUZA,R.J.; CARVALHO, J.G.; YURI,J.E.; RESENDE, G.M. Efeito do cloreto de potássio via fertirrigação na produção de alface americana em cultivo protegido.Horticultura Brasileira, v.20, n.2, 2002.

PURQUERIO, L. F. V. “Crescimento, produção e qualidade de rúcula (Eruca sativa Miller) em função do nitrogênio e da densidade de plantio" Tese (Doutorado em Agronomia/ 
Horticultura) - Faculdade de Ciências Agronômicas, Universidade Estadual Paulista, Botucatu, p. $138,2005$.

VIANA, E. M.; KIEHL, J. C. Doses de nitrogênio e potássio no crescimento do trigo. Bragantia, v. 69, n. 4, p. 975-982, 2010. 